\title{
Birth outcome and HIV infection among labouring women in Assosa Hospital, Southwest Ethiopia
}

\author{
Asaye Chekol $^{1}$
}

\begin{abstract}
Background: Perinatal mortality rate is a sensitive indicator of quality of care provided to women in pregnancy, at and after childbirth and to the newborns in the first week of life. Regular prenatal audit would help in identifying all the factors that play a role in causing prenatal deaths and thus help take appropriate interventions to reduce the avoidable once, at least. Knowledge of mothers' HIV positive status provides an entry point for appropriate care of the mothers, HIV exposed infants and other family members including children.

Objectives: To assess birth outcomes and the magnitude of HIV infection among labouring mothers in Assosa hospital.

Method: An institution-based cross-sectional survey was conducted in Assosa hospital from September 2008 to August 2009. A total of 581 labouring women were interviewed using a pretested structured questionnaire.

Results: Data was obtained from 581 mothers. HIV infection among labouring women was 6.5\%. Mothers, who had primary education $[\mathrm{AOR}=4.76,95 \% \mathrm{CI}=1.81-12.52]$, no formal education $[\mathrm{AOR}=3.05,95 \% \mathrm{CI}=1.08-8.64]$, mothers with two or more pregnancies $[\mathrm{AOR}=2.64,95 \% \mathrm{CI}=1.08-6.49]$, and Muslims $[\mathrm{AOR}=0.32,95 \% \mathrm{CI}=0.13-0.82]$ were the independent predictors of HIV infection. There were 525 live births. The prenatal deaths were 69 , making an overall prenatal mortality of 119 per 1000 total births. Bivariate analysis showed that rural women, women who had no ANC visit, mothers aged 30 years and above, with no formal education, housewives, Berta women of in ethnic group and Muslim were crudely associated with higher risk of prenatal mortality.

Conclusion: The study identified high level of perinatal mortality and HIV infection. This study calls for effective antenatal care, delivering service, and a coordinated referral system and community interventions including HIV counseling, testing (VCT), treatment and support. [Ethiop. J. Health Dev. 2011;25(1):10-16]
\end{abstract}

\section{Introduction}

The World Health Organization estimates that more than nine million infants die before birth or in the first few weeks of life each year, and that nearly all of these deaths occur in developing countries. Most of these deaths are caused by infectious diseases; pregnancy-related complications such as placenta previa and abruptio placentae; delivery-related complications, including intrapartum asphyxia, birth trauma, low birth weight and premature birth (1).

The perinatal mortality rate is five times higher in developing than in developed regions: 10 deaths per 1000 total births in developed regions; 50 per 1000 in developing regions and over 60 per 1000 in the least developed countries. It is the highest in Africa, with 62 deaths per 1000 births (2).

Studies demonstrate the high level of perinatal mortality and morbidity in developing countries which the research identified the causes and repeatedly emphasized the need for antenatal care and availability of trained personnel to attend women during labour and delivery (1). Perinatal mortality is an important indicator of maternal care and of maternal health and nutrition; it also reflects the quality of the obstetric and paediatric care available. Although social factors exert the main influence on the outcome of a birth, as societies advance good medical care tends to play a greater role (2).
A facility-based study in Pakistan reported that the perinatal mortality rate (PNMR) was 97.2/1000 total births and the still birth rate 73.4/1000 total births (3). Another study from Iraq reported that the perinatal mortality rate of $38.5 \%$. Males, and low birth weight babies were at risk of PMR. Gestational age, Apgar score, maternal age, residence, previous medical history, previous prenatal death, and plurality were found to be predictor of PMR (4).

Hypertensive disease of mothers, mechanical causes (ruptured uterus, cord prolapse, CPD), intrapartum hemorrhage (APH), low birth weight (LBW), congenital malformation, maternal medical disorders like jaundice, anemia and diabetes and neonatal infections and asphyxia were identified as cause of prenatal deaths $(4,5)$.

Perinatal mortality rates in Ethiopia are among the highest in the world and stem from a range of socioeconomic, political and demographic factors. According to the EDHS 2005, national and regional (BenishanigulGumuz) prenatal mortality rate is 37 per 1000 total births and 42 per 1000 total births respectively. Factors such as education, religion, accessibility of health services, socioeconomic status, demographic characteristics like sex of the child, mother's age at birth, birth order, birth weight, and the like are found to affect mortality rates (6). Another study in Dire Dawa found that PMR of 73/ 1000

${ }^{T}$ Assosa Hospital, P.O. Box 77 Assosa, Ethiopia, Email asayechekol@yahoo.com, Tel. 0911402590/ 0577750624, Fax: 0577750062 
live births and ANC, birth weight, preterm, place of delivery, age of the mothers, marital status, parity, and income were found to affect prenatal mortality (7). An institution-based study in Addis showed that maternal illiteracy, birth interval, birth weight, lack of prenatal care and a history of past perinatal loss were found to be predictors of prenatal mortality (8).

The most significant source of HIV infection in children and infants is the transmission of HIV from mother to child during pregnancy, child birth, or breastfeeding. About $15-40 \%$ of children born to HIV-positive mothers become infected. Without treatment, around $15-30 \%$ of babies born to HIV-positive women will become infected during pregnancy and delivery. A further $10-20 \%$ will become infected through breastfeeding $(9,10)$.

AIDS in Ethiopia $6^{\text {th }}$ report showed that unadjusted HIV prevalence among pregnant women attending ANC clinic was 5.3\%, and the 15-24 and 25-34 year age groups, had the highest HIV prevalence of $5.6 \%$ in the rural and urban areas respectively (11). In 2009, about 84,000 and 684 pregnant women were living with HIV in the country and in Benishanigul-Gumuz, respectively. Adult HIV prevalence was $2 \%$ in the region (12). ANC-based HIV prevalence in urban sites was $7.6 \%, 8.5 \%, 5 \%, 4.2 \%$, and $0.9 \%$ in Assosa hospital, Pawe hospital, Dabate Health Center, Kamash Health Center and Menge Health Center, respectively (11). Studies in Afar and Gondar on pregnant women attending ANC showed $19.7 \%$ and $9.6 \%$ tested HIV positive, respectively $(13,14)$.

The objectives of this study were, therefore, to assess birth outcome and the magnitude of HIV infection among labouring women in Assosa hospital. It is believed that the result of this study will help policy makers' understand the factors of prenatal mortality in the region and the burden of HIV and serve as an important tool for any possible intervention aimed at improving the gaps identified.

\section{Methods}

An institution-based cross-sectional survey to assess birth outcome and the magnitude of HIV infection among mothers that delivered was carried out in Assosa Hospital from September 2008 to August 2009. Assosa Hospital is a regional referral hospital located in Assosa town of Benishangul-Gumuz, which is located $670 \mathrm{~km}$ from Addis Ababa. The hospital has a total of 108 beds of which 20 are allocated to the maternity unit. There were 6 midwives, three general practitioners and one general surgeon during the time of the study. Prevention of mother to child transmission of HIV service is also available in the hospital.

Study participants were admitted to the hospital for delivery within the study period and mothers, who were willing to participate voluntarily and able to communicate, were included in the study. Mothers who were admitted after delivery were excluded. The number of study participants for the survey was calculated using the formula for single population. The assumption was $17.8 \%$ of pregnant women attending PMTCT sites, had tested HIV positive in the region (11), with $3.25 \%$ precision and $95 \%$ confidence of certainty. The required total sample size was 586 with $10 \%$ contingency and interviewing was done consecutively until the sample size, reached.

The data collection tool used was a structured pretested questionnaire prepared in Amharic. The process was interviewer-administered supported by some form of clinical evaluation, and serology was done for HIV testing. The questionnaire consisted of: sociodemographic characteristics, obstetric information, clinical conditions at admission, mode of delivery and their outcome and the HIV sero-status of clients. Eight midwives, who were given two-days training, were involved in the data collection. They are conversant in their local knowledge. Pretesting of the questionnaire was undertaken in a similar setting before the actual data collection took place. Data collectors also carried out HIV counseling and testing in line with the protocol of the national opt-out strategy (15). An investigator supervised the whole process of data collection on a daily basis.

Ethical approval was secured from the BenishangulGumuz Health Bureau and permission to carry out the study was obtained from Assosa hospital. Each study participant was informed about objective of the study, the interviewer discussed the issue of confidentiality and participants were asked for their verbal consent before the actual interview. Participants were informed that they have the right to refuse or discontinue participating in the research without affecting the service they get from the facility. Privacy was kept by conducting the interview privately in a single room. No identifier of the participating women was collected. All responses were kept confidential.

The collected data were entered into a computer, edited and cleaned using Epi info. Data were transferred and analyzed using SPSS version 13 software. Statistical tests such as chi-square, and measures of association (odds ratio (OR) with $95 \%$ confidence interval (CI) and $\mathrm{P}$ value) were used as deemed necessary. Binary logistic regression analysis was performed to control potential confounding factors.

In this study, the following operational definitions were used:

Institutional maternal deaths: death of mothers during labour, intervention and after delivery until discharged but within 42 days in Assosa hospital.

Stillbirth: number of babies born dead after 28 weeks of gestational age. 
Early neonatal death: death of the newborn till discharged but within seven days.

Perinatal mortality; it is foetal death starting from 28 weeks of gestational age and the death of new born in the first week of life, which comprises late foetal and early neonatal deaths.

Antenatal care visit: with at least one ANC visit by skilled health personnel in the current pregnancy.

Anemia: hemoglobin below $8 \mathrm{~g} / \mathrm{dl}$.

\section{Results}

A total number of 581 (99.1\% response rate) labouring women attending delivery services in Assosa hospital participated in the study. The age ranged from 15-42 years and the majority of the respondents $487(83.8 \%)$ were under the age of 30 years. The mean $( \pm 1 \mathrm{SD})$ age of the study participants was $24.1( \pm 4.8)$ years (median=23 years) and $378(65.1 \%)$ of them were from urban areas. Of the respondents, $332(57.1 \%)$ were Christian while 249 (42.9\%) were Muslims. Amhara, Oromo and Berta constituted 35.1\% (204), 33\% (192) and 15.3\% (89) ethnicity wise, respectively. About $367(63 \%)$ of the respondents had attended formal education, 563 (96.9\%) of respondents were married, and 449 (77.3\%) were housewives at the time of the study. Two hundred thirty seven $(40.8 \%)$ of the mothers were pregnant for the first time. Four hundred fifty two $(77.8 \%)$ of the respondents had received antenatal care during current pregnancy, (Table 1).

On admission, $474(81.5 \%)$ of the mothers were at different stages of labour without complication and 107 (18.5\%) were labouring mothers with complications as shown in Table 2. The complications identified during admission were intrauterine fetal death $(n=32,29.9 \%)$, pregnancy related hypertension $(\mathrm{n}=19,17.8 \%)$, anemia $(\mathrm{n}=18,16.8 \%)$, premature rupture of the membrane $(\mathrm{n}=16,15 \%)$, uterine rupture $(\mathrm{n}=16,15 \%)$ and antepartam hemorrhage $(n=14,13.1 \%)$. Of the 581 deliveries registered during the study period, 79 (13.6\%) were with caesarean section. The indications for caesarean section were: cephalo-pelvic disproportion $(n=37,46.8 \%)$, fetal distress $(n=19,24.1 \%)$, antepartam hemorrhage $(n=6,7.6 \%)$, malpresentation $(n=6,7.6 \%)$ and other indications such as failed vaccum, failed augmentation, prolonged labour, cord prolapse and previous scare $(n=11,13.9 \%)$. Thirty eight $(6.5 \%)$ of the mothers understudy were HIV positive.

There were 56 stillbirths and 13 early neonatal deaths making an overall perinatal mortality of $69(\mathrm{PMR}=118.8$ per 1000 total births). Of the total live births, 295 $(56.2 \%)$ were males while $230(43.8 \%)$ were females. The mean birth weight was $3472 \pm 532$ grams. The mean birth weight of the male babies was greater than that of the female, (3526.4 vs. 3403.9 gram respectively), (Table 2).
There were 11 maternal deaths during the study period making MMR of 2095 per 100,000 live births. Causes of maternal deaths were: bleeding and uterine rupture $(n=5)$, infection $(n=3)$, hypertension $(n=2)$ and cardiac problem $(n=1)$. Six of the mothers developed vesico-vaginal fistula.

\begin{tabular}{|c|c|c|}
\hline Variables & Frequency & Percent \\
\hline $\begin{array}{l}\text { Age of mothers in years } \\
(\text { Mean } \pm S D)=24.08 \pm 4.84)\end{array}$ & & \\
\hline $15-19$ & 87 & 15.0 \\
\hline $20-29$ & 400 & 68.9 \\
\hline $30-42$ & 94 & 16.1 \\
\hline Place of residence & & \\
\hline Rural & 203 & 34.9 \\
\hline Urban & 378 & 65.1 \\
\hline Religion & & \\
\hline Christian & 332 & 57.1 \\
\hline Muslim & 249 & 42.9 \\
\hline Ethnic group & & \\
\hline Amhara & 204 & 35.2 \\
\hline Oromo & 192 & 33.0 \\
\hline Berta & 89 & 15.3 \\
\hline Others* & 96 & 16.5 \\
\hline Educational status & & \\
\hline High school and above & 240 & 41.3 \\
\hline Primary & 127 & 21.9 \\
\hline No formal education & 214 & 36.8 \\
\hline Marital status & & \\
\hline Married & 563 & 96.9 \\
\hline Others** & 18 & 3.1 \\
\hline Number of pregnancies & & \\
\hline 1 & 237 & 40.8 \\
\hline $2+$ & 344 & 59.2 \\
\hline Antenatal care visit & & \\
\hline Yes & 352 & 77.8 \\
\hline No & 129 & 22.2 \\
\hline Occupation & & \\
\hline Housewives & 449 & 77.3 \\
\hline Non-housewives & 132 & 22.7 \\
\hline
\end{tabular}
Others* Tigre(42), Gurage(40), Shinsha(7), Gumuz(3),Siltie(2), Kefa(1),Hadya(1), Others $^{* *}$ Unmarried (9), widowed (6), divorced (3), Nonhousewives: Govermental employed (68), Student (29), Daily laborer (17), merchant (7), house maid (5), private employed (6) 
Table 2: Admission diagnosis, mode of delivery and sex and neonatal outcome of 581 women delivered at Assosa Hospital, southwest Ethiopia

\begin{tabular}{|c|c|c|}
\hline Variables & Frequency & Percent \\
\hline \multicolumn{3}{|l|}{$\begin{array}{l}\text { Conditions at admission } \\
(n=581)\end{array}$} \\
\hline Labour without complication & 474 & 81.5 \\
\hline Labour with complication & 107 & 18.5 \\
\hline \multicolumn{3}{|l|}{ Mode of Delivery $(n=581)$} \\
\hline SVD & 306 & 52.6 \\
\hline SVD+ Episotomy & 89 & 15.3 \\
\hline SVD+episotomy+vaccum & 91 & 15.7 \\
\hline Caesarian section (CS) & 79 & 13.6 \\
\hline Laparatomy for ruptured uterus & 16 & 2.8 \\
\hline \multicolumn{3}{|l|}{$\begin{array}{l}\text { Condition of the newborn at birth } \\
(n=581)\end{array}$} \\
\hline Alive on discharge & 512 & 88.2 \\
\hline Early neonatal death & 13 & 2.2 \\
\hline Stillbirth & 56 & 9.6 \\
\hline \multicolumn{3}{|l|}{ Sex of alive newborn $(n=525)$} \\
\hline Male & 295 & 56.2 \\
\hline Female & 230 & 43.8 \\
\hline Spontaneous & vaginal & delivery \\
\hline
\end{tabular}

Table 3: Association of socio-demographic and some obstetric factors on HIV infection among 581 women delivered at Assosa hospital, southwest Ethiopia, Sept. 2009

\begin{tabular}{|c|c|c|c|c|}
\hline \multirow{2}{*}{ Variables } & \multicolumn{2}{|c|}{ HIV Infection } & \multirow{2}{*}{ COR (95\% Cl) } & \multirow{2}{*}{ AOR (95\% CI) } \\
\hline & Yes (\%) & No $(\%)$ & & \\
\hline \multicolumn{5}{|l|}{ Place of residence } \\
\hline Rural & $5(2.5)$ & $198(97.5)$ & 1.00 & 1.00 \\
\hline Urban & $33(8.7)$ & $345(91.3)$ & $3.79(1.46,9.86)^{*}$ & $2.66(0.82,8.65)$ \\
\hline \multicolumn{5}{|l|}{ Age } \\
\hline $15-19$ & $3(3.4)$ & $84(96.6)$ & 1.00 & 1.00 \\
\hline $20-29$ & $32(8)$ & $368(92)$ & $2.43(0.73,11.66)^{*}$ & $2.11(0.52,8.80)$ \\
\hline $30+$ & $3(3.2)$ & $91(96.8)$ & $0.92(0.18,4.70)$ & $0.62(0.99,4,15)$ \\
\hline \multicolumn{5}{|l|}{ Antenatal care visit } \\
\hline No & $3(2.3)$ & $126(97.7)$ & 1.00 & 1.00 \\
\hline Yes & $35(7.7)$ & 417(92.3) & $3.53(1.07,11.66)^{*}$ & $1.59(0.34,7.35)$ \\
\hline \multicolumn{5}{|l|}{ Educational status } \\
\hline High school and above & $11(4.6)$ & $229(95.4$ & 1.00 & 1.00 \\
\hline Primary & $15(11.8)$ & $112(88.2)$ & $2.79(1.24,6.27)^{*}$ & $4.76(1.81,12.52)^{*}$ \\
\hline No formal education & $12(5.6)$ & $202(94.4)$ & $1.23(0.53,2.86)$ & $3.05(1.08,8.64)^{*}$ \\
\hline \multicolumn{5}{|l|}{ Number of pregnancies } \\
\hline 1 & $10(4.2)$ & $227(95.8)$ & 1.00 & 1.00 \\
\hline $2+$ & $28(8.1)$ & 316(91.9) & $2.01(0.96,4.22)$ & $2.64(1.08,6.49)^{\star}$ \\
\hline \multicolumn{5}{|l|}{ Marital status } \\
\hline Married & $35(6.2)$ & $528(93.8)$ & 1.00 & 1.00 \\
\hline Others ${ }^{* *}$ & $3(16.7)$ & $15(83.3)$ & $3.02(0.83,10.92)$ & $3.22(0.61,6.94)$ \\
\hline \multicolumn{5}{|l|}{ Ethnic group } \\
\hline Amhara & $17(8.3)$ & $187(91.7)$ & 1.00 & 1.00 \\
\hline Oromo & $13(6.8)$ & 178(93.2) & $0.80(0.38,1.69)$ & $0.74(0.33,1.67)$ \\
\hline Berta & & & & \\
\hline Others* & $8(4.3)$ & $177(95.7)$ & $0.50(0.21,1.18)$ & $0.61(0.23,1.64)$ \\
\hline \multicolumn{5}{|l|}{ Occupation } \\
\hline Housewives & $29(6.5)$ & 420 & 1.00 & 1.00 \\
\hline Non-housewives & $9(6.8)$ & $123(93.2)$ & $1.06(0.49,2.30)$ & $1.39(0.48,4.07)$ \\
\hline \multicolumn{5}{|l|}{ Religion } \\
\hline Christian & $31(9.3)$ & $301(90.7)$ & 1.00 & 1.00 \\
\hline Muslim & $7(2.8)$ & 242(97.2) & $0.28(0.12,0.65)^{*}$ & $0.32(0.13,0.82)^{*}$ \\
\hline
\end{tabular}

${ }^{*}=$ Significantly associated; 1=Referent category

The effects of place of residence, age, antenatal care visit, educational status, ethnicity, occupational status, HIV infection and religion on prenatal mortality were assessed using bivariate and multivariate analysis. On bivariate analysis, perinatal mortality was found to be higher among rural women $(\mathrm{p}=22.2 \%, \mathrm{COR}=4.20$,
The odds of acquiring HIV infection was significantly higher among mothers with primary education $(\mathrm{p}=11.8 \%$, $\mathrm{AOR}=4.76,95 \% \mathrm{CI}=1.81-12.53)$, no formal education $(\mathrm{p}=5.6 \%, \mathrm{AOR}=3.05,95 \% \mathrm{CI}=1.08-8.64)$, two or more pregnancies $(\mathrm{p}=8.1 \%, \mathrm{AOR}=2.64,95 \% \mathrm{CI}=1.08-6.49)$. On the other hand, the odds of HIV infection was significantly lower among Muslims $(p=2.8 \%$, $\mathrm{AOR}=0.32,95 \% \mathrm{CI}=0.13-0.82$ ). Place of residence and antenatal care, which showed significant difference in the crude analysis, fell short of statistical significance in the adjusted analysis (Table 3 ). 
$\mathrm{COR}=3.43,95 \% \mathrm{CI}=1.45-8.12$ ), and among Muslims $(\mathrm{p}=18.1 \%, \mathrm{COR}=2.83,95 \% \mathrm{CI}=1.67-4.96) . \quad$ But all variables failed to show any statistical significant association when adjusted (Table 4).

Table 4: Association of socio-demographic and other factors $(n=581)$ on perinatal mortality at Assosa hospital, southwest Ethiopia, Sept. 2009

\begin{tabular}{|c|c|c|c|c|}
\hline \multirow{2}{*}{ Variables } & \multicolumn{2}{|c|}{ Perinatal mortality } & \multirow[b]{2}{*}{ COR (95\% CI) } & \multirow[b]{2}{*}{ AOR (95\% CI) } \\
\hline & Yes (\%) & No $(\%)$ & & \\
\hline \multicolumn{5}{|l|}{ Place of residence } \\
\hline Rural & $45(22.2)$ & $158(77.8)$ & $4.20(2.47,7.14)^{*}$ & $1.91(0.91,4.00)$ \\
\hline Urban & $24(6.3)$ & $354(93.7)$ & 1.00 & 1.00 \\
\hline \multicolumn{5}{|l|}{ Age } \\
\hline $15-19$ & $7(8.0)$ & $80(92.0)$ & 1.00 & 1.00 \\
\hline $20-29$ & $44(11.0)$ & $356(89)$ & $1.41(0.61,3.25)$ & $1.12(0.91,2.68)$ \\
\hline $30+$ & $18(19.1)$ & $76(80.0)$ & $2.70(1.07,6.84)^{*}$ & $1.48(0.54,4.07)$ \\
\hline \multicolumn{5}{|l|}{ Antenatal care visit } \\
\hline No & $36(22.9)$ & $93(72.1)$ & $4.92(2.91,8.29)^{*}$ & $1.75(0.80,3.79)$ \\
\hline Yes & $33(7.3)$ & $419(92.7)$ & 1.00 & 1.00 \\
\hline \multicolumn{5}{|l|}{ Educational status } \\
\hline High school and above & $14(5.8)$ & $226(94.2)$ & 1.00 & 1.00 \\
\hline Primary & $11(8.7)$ & $116(91.3)$ & $1.53(0.67,3.48)$ & $0.98(0.39,2.46)$ \\
\hline No formal education & $44(20.6)$ & $170(79.4)$ & $4.18(2.22,7.87)^{*}$ & $1.42(0.66,3.26)$ \\
\hline \multicolumn{5}{|l|}{ Ethnic group } \\
\hline Amhara & $19(9.3)$ & $185(90.7)$ & 1.00 & 1.00 \\
\hline Oromo & $22(11.5)$ & $170(88.5)$ & $1.26(0.66,2.41)$ & $1.12(0.57,2.20)$ \\
\hline Berta & $24(27)$ & $65(73)$ & $3.60(1.85,6.99)$ & $1.76(0.79,3.91)$ \\
\hline Others* & $4(4.2)$ & $92(95.8)$ & $0.42(1.14,1.28)$ & $0.51(0.16,1.57)$ \\
\hline \multicolumn{5}{|l|}{ Occupation } \\
\hline Housewives & $63(14)$ & $386(86)$ & $3.43(1.45,8.12)$ & $1.71(0.62,4.65)$ \\
\hline Non-housewives & $6(4.5)$ & $126(95.5)$ & 1.00 & 1.00 \\
\hline \multicolumn{5}{|l|}{ HIV infection } \\
\hline Yes & $4(10.5)$ & $34(89.5)$ & $0.86(0.29,2.51)$ & $1.62(0.52,5.10)$ \\
\hline No & $65(12)$ & $478(88)$ & 1.00 & 1.00 \\
\hline \multicolumn{5}{|l|}{ Religion } \\
\hline Christian & $24(7.2)$ & $308(92.8)$ & 1.00 & 1.00 \\
\hline Muslim & $45(18.1)$ & $204(81.9)$ & $2.83(1.67,4.96)^{*}$ & $1.31(0.66,2.60$ \\
\hline
\end{tabular}

${ }^{*}=$ Significantly associated

$1=$ Referent category

\section{Discussion}

Perinatal mortality rate is a sensitive indicator of the quality of care provided to women in pregnancy, at and after childbirth and to the newborns in the first week of life. Regular perinatal study would help in identifying all the factors that play a role in causing perinatal deaths and thus help in taken appropriate interventions to reduce avoidable perinatal deaths (2). Offering HIV testing to all pregnant women, as a standard practice is the first step toward preventing HIV infection in the unborn child. Knowledge of mothers' HIV-positive status provides an entry point for appropriate care of the mother, HIVexposed infant and other family members including children. This institution based cross-sectional survey assessed the birth outcome and HIV infection among women attending delivery services in Assosa hospital.

The magnitude of HIV infection in this study was $6.5 \%$, which was lower than that of Assosa hospital and the regional prevalence of HIV among pregnant women from PMTCT clinics as $7.6 \%$ and $17.8 \%$, respectively (11). On the other hand, higher rates of HIV infection, $19.7 \%$, $11.9 \%, 30 \%$ and $10.1 \%$ among pregnant women were reported from Afar, Gondar, Botswana and Cameroon, respectively $(13,14,16,17)$. These are higher than reported from Ghana (18). This difference could be due to the difference in HIV prevalence among regions; among the countries and the methodologies they followed.

As expected, higher rates HIV infection who observed among urban women but the finding was not statistically significant when adjusted with other variables. A study on pregnant women in Afar had found similar findings (13). On the contrary, a study from Nigeria found high rates of HIV infection among rural pregnant women (19). Though high rates of HIV infection were observed among mothers who had ANC visit on current pregnancy, the finding was not statistically significant when adjusted with other variables. A study from Cameroon had found that the number of ANC visits was associated with HIV infection (16). High rates of HIV infection among mothers that received ANC is that the majority of ANC attendees are urban women with expected is higher HIV infection.

The educational status of the women was found to be an independent predictor of HIV infection. HIV infections 
among women with this any formal education and with primary level education were 3.19 and 4.6 times higher respectively compared to those who had high school and above level of education. A study on labouring mothers in Cameroon had found high rates of HIV infection among educated mothers (16). Another study from Nigeria on pregnant women also reported high rates for their with education high level education (19). The lower the level of education as risk of HIV infection, found in this study can be explained by the fact that mothers, who had no or lower level of education may not be aware of HIV transmission and don't practice safe sex and or they may be economic dependents.

The number of experience pregnancies was found to be a predictor of HIV infection in this study. A Study conducted on labouring mothers in Cameroon had found similar findings (19). A significant association was found between religion and HIV infection. Being Muslim was found to be less likely to be infected in this study. On the contrary, a Nigerian study had found that the Christian religion was associated with a lower risk (20). The low rates of HIV infection in this study may be explained by the fact that majority of Muslim women in this region are culturally confined to their husbands and guard their virginity for marriage.

In this study, the perinatal mortality rate was 118.8 per 1000 total births. This finding is much higher than studies in Pakistan, Iraq and Tanzania which showed perinatal mortality of $97.2 / 1000,38.5 \% / 1000$, and $38 / 1000$ total births, respectively $(3,4,21)$. An institution based study in Jimma reported a perinatal mortality of 138.9/ 1000 live births, which was higher than this study (22). Ethiopian DHS 2005 reported national and regional perinatal mortality of 37 per 1000 and 42 per1000 total births respectively (11). The difference can be explained by time of study, method of study (population or facility), and site of study.

As it is expected, rural residence was associated with a higher perinatal mortality compared with urban residence. However, when adjusted for other variables, place of residence didn't retain its significance. Rural areas in most developing countries tend to be poorer and more difficult to reach with healthcare services compared with urban areas. Association between rural residence and increased prenatal mortality has also been reported in studies done in Iraq, Tanzania and Uganda (4, 23, 24). Antenatal care provides pregnant women the knowledge of how to care for their pregnancy and is used to identify high-risk mothers, and, it is the determinant factor in reducing prenatal mortality $(8,25,26)$. In this study mothers who had no ANC visit were at high risk of prenatal mortality. However, no association was reported between ANC and prenatal mortality from a study in Iraq (4).

This study showed that prenatal mortality was 2.7 times higher among women aged 30 years and above than women aged 15-19 years. However, when adjusted for other variables, it lost its significance. These differs from the study from Dire Dawa, in which mothers thirty five and above years were less at risk for prenatal mortality than mothers 15-19 years (7). A study in India had shown that the relationship between age of the mother and prenatal mortality is considered to be a ' $U$ 'shaped one (26).

Maternal education is considered as one of the most important factors for a better outcome of pregnancy since it provides the mother with the necessary skill. Educational level can also affect her reproductive behavior and also increase her skill in health care practices such as contraceptive use, nutrition, hygiene, and preventive care and disease treatment (27). In this study, mothers who had no formal education were at a higher risk of prenatal mortality on crude analysis. A study in Tanzania had also found similar results (23).

Perinatal mortality was higher among the Berta ethnic groups and Muslims but both lost their association when adjusted. Bertas as a risk factor for prenatal mortality could be explained by the fact that the majority of the Being them reside in the rural are usually and deliver at home seeking medical service late. It is also possible that the ethnic group with higher risks have cultural values that limit women's opportunities to make their own decision.

A mother's occupation may involve physical strain or exposures that could impose risks on her pregnancy. Hence, housewives were crudely associated with higher risk of perinatal mortality compared to non-housewives. A Tanzanian study had also shown that mothers with professional occupations had lower risk of prenatal mortality compared to mothers with other occupations (23). As risk of perinatal mortality being housewife can be explained by the fact that the majority of housewives are economically dependent on their husbands and aren't free to decide by themselves.

This study was an institution-based one in which the study population may not be representative. The overall perinatal mortality in this area is likely to have been underestimated as women and their newborns were usually discharged from the hospital within 24 hours of delivery, if the Apgar score of the baby was 8 or higher and there were no other medical indications for inhospital treatment. Follow-up was not made after the discharge, hence most early neonatal deaths reflect those occurring within 24 hours of delivery.

In conclusion, the study revealed high perinatal mortality rate compared to many other studies. Rural women, those who had no ANC visit, older women, housewives, Muslims, Berta and women with no formal education were crudely associated with high risk of perinatal mortality. Educational status, religion and the number of previous pregnancies were independent predictors of 
HIV infection. High prenatal and maternal mortality should be tackled by improving hospital management, addressing primary and secondary delay (access to hospital, transport facility, a well-organized referral system). High level of HIV infection, found in this study also calls for strengthening the comprehensive approach that comprises: primary prevention of HIV-infection, prevention of unintended pregnancies among HIV infected mothers, prevention of HIV transmission from HIV-infected mother to their offspring, and providing of care and support to women infected with HIV, their infants and their families.

\section{Acknowledgements}

The Benishangul-Gumuz Regional Health Bureau is greatly acknowledged for its financial support. I would like to extend my appreciation to data collectors and all nurses working at labour ward and maternity ward for their valuable support. I am also grateful to all mothers who participated in this study.

\section{References}

1. World Health Organization 2005. Global Survey on Maternal and Prenatal Health, Geneva; 2006.

2. World Health Organization Neonatal and Prenatal Mortality Country, Regional and Global Estimates. 2006.

3. Bhutta S, Kerioje R, Noorani KJ, Bhutta ZA. An audit and trends of prenatal mortality at the Jinnah Postgraduate Medical Centre, Karachi. J pak Med Assoc 2007;57(4):168-72.

4. Al-Hiali SJ, Al-Mashhadani WS. Prenatal mortality rate in Al-Ramadi Maternity and Children's Hospital, western Iraq. Saudi Med J 2009;30(10):1296-300.

5. Frost 143-6.Maternal and prenatal deaths in an Addis Ababa Hospital, 1980. Ethiop Med J 1984 Jul; 22(3):

6. Central Statistics Agency: Ethiopia Demographic and Health Survey 2005. Ethiopia, Addis Ababa, Central Statistics Agency; 2006.

7. Yakob T. Assessment of pregnancy outcome with emphasis on prenatal and neonatal mortality in Dire Dawa town, Ethiopia. Masters Thesis, 2003.

8. Tilahun S, Gaym A. Past reproductive performance and its correlation with prenatal mortality in the current gestation at teaching hospitals in Addis Ababa, Ethiopia. Ethiop Med J 2008;46(4):313-24

9. UNAIDS. Counseling and Voluntary HIV testing for pregnant women in high HIV prevalence countries. Geneva: Switzerland; 2001.

10. Avert. Prevention of mother to child transmission of HIV in sub-Saharan Africa countries. August 2007, accessed on 13/08/2009. Available from: URL: WWW.avert.org/ motherchild.htm.

11. Federal Ministry of Health of Ethiopia and HAPCO. AIDS in Ethiopia sixth report. Addis Ababa, Ethiopia. September 2006.

12. Federal Ministry of Health. Single point estimate. 2007.
13. Assefa T, Davey G, Dukers $\mathrm{N}$ and et al. Overall HIV-1 prevalence in pregnant women over-estimates HIV-1 in the predominantly rural population of Afar Region. Ethiop Med J 2003;41 (Suppl 1) :43-9.

14. Mullu A, Kassu A and et al. Sero-prevalence of syphilis and HIV-1 during pregnancy in teaching hospital in northwest Ethiopia. Jpn J Infect Di. 2007;60:193-195.

15. FMOH and HAPCO. Guidelines for the Prevention of Mother to Child Transmission of HIV in Ethiopia. July 2007.

16. Kongnyuy Ej and et al. Acceptability of intrapartum HIV counseling and testing in Cameroon. $B M C$ Pregnancy and Childbirth 2009;9:9.

17. Thior I, Gabaitiri L, Grimes J, Shapiro R, Lockman $\mathrm{S}, \mathrm{Kim} \mathrm{S}$ and et al. Voluntary counseling and testing among post-partum women in Botswana. Patient Edu. Couns 2007;65(3):296-302.

18. Holmes CN, Preko PO, Bolds R, Baidoo J, Jolly PE. Acceptance of VCT and treatment for HIV among pregnant women in Kumsi, Ghana. Ghana Med $J$ 2008 March; 42(1): 8-15.

19. Utulu SN, Lawoyen T. Epidemiological features of HIV infection among pregnant women in Makurdi, Benue State, Nigeria. J Biosoc Sci 2007 May; 39(3): 397-408.

20. Lawoyin TO, Adewole DA. Predictors of maternal HIV infection at the primary care level in inner city Ibadan. Int J STD AIDS 2004 Mar; 15(3): 165-8)

21. Mbaruku G, van Roosmalen J, Kimondo I, Bilango F, Bergstrom S. Prenatal audit using the 3-delays model in western Tanzania. Int $J$ Gynaecol Obstet 2009;106(1):85-8.

22. Gaym. A. Prenatal Mortality Audit at Jimma Hospital, South Ethiopia. Ethiopian Journal of Health Development. 2002; 14(3); 335-343.

23. Habib NA, Lie RT, Oneko O, Shao J, Bergsjo P, Daltveit AK. Socio-demographic characteristics and prenatal mortality among singletons in North East Tanzania a registry-based study. $J$ Epidemiol Community Health 2008; 62(35):960-965.

24. Akello B, Nabiwemba E, Zirabamuzaale C, Orach CG. Risk factors for prenatal mortality in Arua regional referral hospital, West Nile, Uganda. East Afr J Public Health. 2008;5(3):180-5.

25. Tadesse E, Afework S, Surafiel Y, Mehari LB. Determinants of prenatal death: a five year retrospective survey at Tikur Anbessa Teaching Hospital. J Obstet Gynaecol East Cent Africa 1989;8(1):15-7.

26. Mavalankar D,Trived R. Levels and risk factors for prenatal mortality in Amhadabad, India. INDIA WHO Bulletin OMS 1991; Vol 69.

27. WHO. Maternal care For The Education of Prenatal And Neonatal Mortality: A Joint WHO /UNICEF Statement. Geneva: WHO; 1986. 